\title{
Tribute to a great pioneer urological surgeon
}

\author{
Dr. Lakshman Sujeewa Attygalle, MBBS(Cey), FRCS(Eng), Senior Consultant \\ Genito Urinary (Urological) Surgeon, passed away on 18th of May 2019.
}

Born in 1933, He was the prodigious son of Sir. Nicholas Attygalle, who was a doyen of Sri Lankan medical history to become the first native Vice Chancellor of the University of Ceylon, the first ENT surgeon in Sri Lanka as well as the first Obstetrician and Gynaecologist. Dr Lakshman Attygalle was also the great grandson of Dr. John Attygalle, MD(Aberdeen), Colonial Surgeon of Ceylon, the first Sinhalese to qualify in Western Medicine. He belonged to a distinguished family of indigenous medical professionals and generations of "Hela Veda Healers" from Madapatha.

Completing his primary education at the Royal college, Colombo, he entered Ceylon

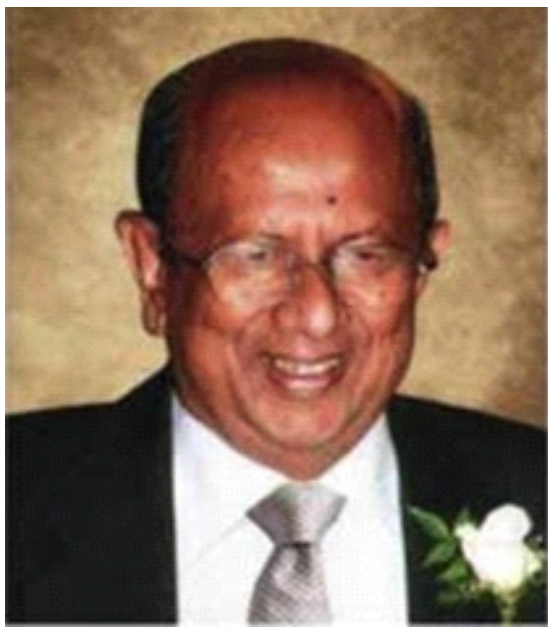
Medical College and completed his undergraduate degree with a 1st class honours. After a brief period of working as a demonstrator in Anatomy and completing his Primary FRCS examination, he worked as a Senior House Officer to Dr. Misso FRCS, another skillful and eminent surgeon of that era .

He branched off to specialise in Genito urinary surgery in 1968, which was at its infancy as a surgical sub specialty. He proceeded to UK on Smith and Nephew scholarship and worked with prominent British surgical giants such as Dr Norman Gibbon FRCS.

Returning from UK in 1968, he was appointed to Kandy General hospital, where he built the first Urology Unit outside Colombo. Later, he took up the post in Colombo General hospital (at present The National Hospital of Sri Lanka) in 1972 and single handedly managed and developed the Unit (present ward 22), to greater heights, up to his retirement in 1993.

His pioneering work on minimally invasive transurethral bladder and prostatic surgery and moved Genito Urinary Surgery (Urology) in to a well-respected finer specialty in Sri Lankan surgical arena making "Genito Urinary Surgery" and the name "Lakshman Attygalle" synonymous.

He was also a skillful surgeon who carried out several thousands of open surgical procedures for urinary stone disease and cancers, with a remarkable success, at an era with minimal supportive facilities such as Intensive Care and trained junior staff. He became the first post graduate trainer in Urology after the establishment of the Post Graduate Institute of Medicine (PGIM) in 1980, beginning with three post graduate trainees, leading to a long line of modern specialist urologists numbering nearly 50 at present.

He was much loved by all categories of staff members in his unit for not only being their leader but also for being a friend-inneed. His generosity extended beyond the staff and reached his patients in a big way as he would pay great attention to their financial restrains in addition to their surgical ailments.

While being a Buddhist by religion he believed more in practicing its principles by giving the poor the health and the wealth. He has held the post of the President of "Kelaniya Vidyalankara Sabha" up to his demise.

At the height of his academic career he held the prestigious post of the President of the College of Surgeons of Sri Lanka from 1992-1993 and served as an executive council member and Honorary Fellow of the Sri Lanka Association of Urological Surgeons (SLAUS).

He also had an illustrious and highly connected social career and thoroughly enjoyed entertaining his friends and colleagues. He was in the board of trustees of the Singhalese sports club (SSC).

DOI: http://doi.org/10.4038/sljs.v37i2.8634

The Sri Lanka Journal of Surgery 2019; 37(2): 38-39 
Dr Attygalle is survived by his wife Dr. Deepthi Attygalle (nee Mendis), retired senior Consultant Anaesthesiologist; and his children, Priyan, Chief Executive, American Express Bank, Saudi Arabia, Ayoma, Consultant Pathologist, Royal Marsden Hospital, London and Amila, Attorney-at-law.

He will be dearly remembered by all his urological trainees and his legend will be narrated and passed on to future generations taking up his beloved speciality.

May his soul rest in peace!

\section{Prof Neville D Perera}

\section{Past President}

College of Surgeons of Sri Lanka 